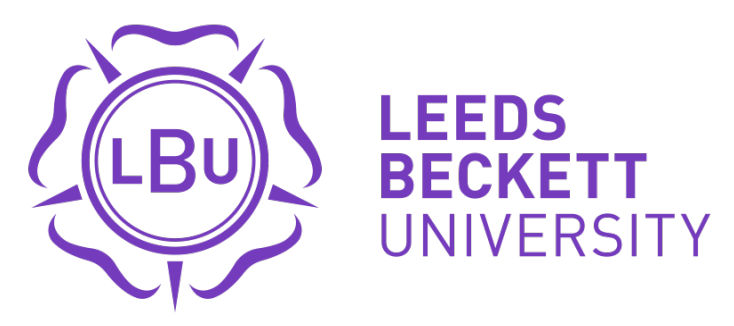

Citation:

Nasir, $M$ and Naidoo, $L$ and Shahbaz, $M$ and Amoo, N (2018) Implications of Oil Prices Shocks for the Major Emerging Economies: A Comparative Analysis of BRICS. Energy Economics, 76. pp. 76-88. ISSN 0140-9883 DOI: https://doi.org/10.1016/j.eneco.2018.09.023

Link to Leeds Beckett Repository record:

https://eprints.leedsbeckett.ac.uk/id/eprint/5378/

Document Version:

Article (Published Version)

Creative Commons: Attribution-Noncommercial-No Derivative Works 4.0

The aim of the Leeds Beckett Repository is to provide open access to our research, as required by funder policies and permitted by publishers and copyright law.

The Leeds Beckett repository holds a wide range of publications, each of which has been checked for copyright and the relevant embargo period has been applied by the Research Services team.

We operate on a standard take-down policy. If you are the author or publisher of an output and you would like it removed from the repository, please contact us and we will investigate on a case-by-case basis.

Each thesis in the repository has been cleared where necessary by the author for third party copyright. If you would like a thesis to be removed from the repository or believe there is an issue with copyright, please contact us on openaccess@leedsbeckett.ac.uk and we will investigate on a case-by-case basis. 


\section{Accepted Manuscript}

Implications of Oil Prices Shocks for the Major Emerging Economies: A Comparative Analysis of BRICS

Muhammad Ali Nasir, Lutchmee Naidoo, Muhammad Shahbaz, Nii Amoo

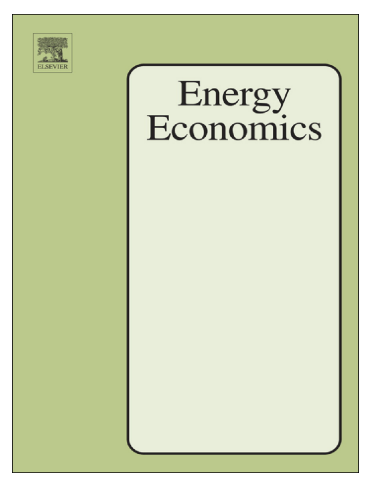

PII:

S0140-9883(18)30395-5

DOI: doi:10.1016/j.eneco.2018.09.023

Reference: ENEECO 4170

To appear in: Energy Economics

Received date: 23 December 2017

Revised date: 31 July 2018

Accepted date: 30 September 2018

Please cite this article as: Muhammad Ali Nasir, Lutchmee Naidoo, Muhammad Shahbaz, Nii Amoo, Implications of Oil Prices Shocks for the Major Emerging Economies: A Comparative Analysis of BRICS. Eneeco (2018), doi:10.1016/j.eneco.2018.09.023

This is a PDF file of an unedited manuscript that has been accepted for publication. As a service to our customers we are providing this early version of the manuscript. The manuscript will undergo copyediting, typesetting, and review of the resulting proof before it is published in its final form. Please note that during the production process errors may be discovered which could affect the content, and all legal disclaimers that apply to the journal pertain. 


\title{
Implications of Oil Prices Shocks for the Major Emerging Economies: A Comparative Analysis of BRICS
}

\author{
Muhammad Ali Nasir ${ }^{1}$, Lutchmee Naidoo, Muhammad Shahbaz, Nii Amoo \\ Leeds Beckett University, Montpellier Business School
}

\begin{abstract}
This study analyses the implications of oil prices shocks for the BRICS economies. We employed a time-varying structural vector autoregressive (TV-SVA) framework in which the sources of time variation are the coefficients and variance-covariance matrix of the innovations. The quarter frequency data for the period of 1987QII - 2017QII is used for the empirical analysis. The key findings suggest that there are substantial differences and asymmetries in the response of these economies to oil shocks. These differences were profound between, and even within, oil exporters and importers. It shows that between major oil exporters i.e. Russia and Brazil the former's economy is rather more intensively influenced by oil prices shocks. Between the two largest net oil importers i.e. India and China, comparatively, the Indian economy seems to be rather more vulnerable to oil prices shocks in terms of their adverse effects on GDP, inflation and balance of trade. The dependence of economies on oil and an increasing level of consumption continue to pose policy challenges for prices and economic stability. The analysis on South Africa also shows negative impacts of oil prices shocks, however, the effects are comparatively more time-variant than other BRICS members. While these asymmetries indicate significant differences in the structure of these economies they also indicate venues of cooperation and stronger trading relationships to overcome the adverse shocks and mutual development.
\end{abstract}

Keywords: Oil Consumption, Trade Balance, Inflation, GDP, Oil Price Shocks, BRICS, TVSVAR Model

JEL Classification: F14, F15, F43, E31, Q41, Q43

\footnotetext{
1 *Corresponding author: Economics, Analytics \& International Business Group, Leeds Business School, Leeds Beckett University, The Rose Bowl, Portland Crescent, Leeds, LS1 3HB, UK, Email: m.a.nasir@leedsbeckett.ac.uk, Telephone: 0044(0)1138123867. Acknowledgment: Authors are thankful to the participants of the 1st International Conference on Energy, Finance and the Macroeconomy (ICEFM) held on November 2017 at Montpellier Business School, France for their kind remarks.
} 


\section{Introduction}

In the recent history of economic and political alliances, the BRICS have turned out to be a systemic and influential block. As it stands, the BRICS economies constitute over $46 \%$ of the world population, over $20 \%$ of the world GDP and $26 \%$ of the world's land mass (IMF, 2015). Furthermore, the combined foreign reserves of the BRICS countries are estimated to be over US\$ 5 trillion, indicating the resilience of these economies and miraculous export-led economic growth in the recent history of global trade. The members of the BRICS increasingly recognise themselves as a group, starting from the interaction of Foreign Ministers in 2006, which led to the annual summit of the Heads of State in 2009 when the depth and scope of the dialogue among the members was further enhanced. Importantly, the remarkable growth in the BRICS economies has been significantly led by their export sectors. The statistics speak clear and loud, according to statistics from the World Trade Organization (WTO), the participation of BRICS in global exports more than doubled between 2001 and 2011 , from $8 \%$ to $16 \%$. In just over a decade, the total size of exports has grown more than $500 \%$, while total global exports grew 195\% in the same period. Between 2002 and 2012, intra-BRICS trade increased 922\%, from US\$ 27 to 276 billion, while for the period of 20102012, BRICS' international trade rose $29 \%$, from US\$ 4.7 to 6.1 trillion dollars. Therefore, in a fairly short span of time, the BRICS has become a new and promising political and economic entity. Concomitantly, the size, significance and swift growth of the BRICS economies possess ecological challenges for the whole world.

Despite the remarkable success, since Global Financial Crisis (2008) and particularly in the last couple of years, the synergy between BRICS has begun to break down. Some of the BRICS economies, notably the slower growth in China, political changes in Brazil, economic sanctions on Russia ${ }^{2}$, a slump in oil prices and steadily falling commodity prices have contributed to this. The World Bank in her report Global Economic Prospects (2016) has highlighted these downside risks ${ }^{3}$ from the emerging markets for the growth in 2016. The BRICS are made up of oil exporting countries (Russia and Brazil); oil importing countries (Indian, China and South Africa). In terms of its importance, oil is one of the most traded commodity in the world. As it stands, the total size of the oil market is over US\$ 1.7 trillion

\footnotetext{
${ }^{2}$ See Dreger et al (2016) on the impact of recent sanctions on Russia and Implications for its economy.

${ }^{3}$ The World Bank (2016) in her report cautioned that there could be a more protracted slowdown across large emerging markets which could have substantial spillovers to other developing economies, and eventually hold back the recovery in advanced economies. For further details please refer to the report available at < http://www.worldbank.org/en/publication/global-economic-prospects >
} 
(EIA, 2016). This importance is due to its status as the primary input in the production process and it is a commodity that will most likely be traded for many more years to come (Rafiq et al. 2016) ${ }^{4}$. Nevertheless, it is projected that global oil demand will continue to increase until at least 2035, so does the oil production reaching double or even triple of its current levels (Reynolds, 2014). This then also implies ecological challenges the world would face. Daily global oil consumption is expected to grow from 89 million barrels in 2012 up to 109 million barrels in 2035 (Statista, 2017). Concomitantly, dynamics and large fluctuations in global oil prices could affect the economies of the BRICS in different ways and therefore this poses a whole set of new challenges for the BRICS countries and also provides rationale and motivation for the subject study.

It is prima facie that economic growth in the BRICS economies have been export-led and resulted in major surpluses in their current accounts, especially for Brazil, China and Russia. It then raises an intuitive question of what constitutes the tradable of these economies. The comparative analysis of the largest imports and exports of BRICS countries suggests that oil and petroleum products are the largest import as well as the second largest export of the BRICS countries. Accordingly to the Brazilian Ministry of Finance (2014) in the year 2010, $15.5 \%$ of exports by the BRICS countries constituted oil and petroleum, while $19.2 \%$ of imports were also oil and petroleum ${ }^{5}$. Figure-1 is a good and concise depiction of dynamics of demand and supply of oil in BRICS countries over a period of two and half decades.

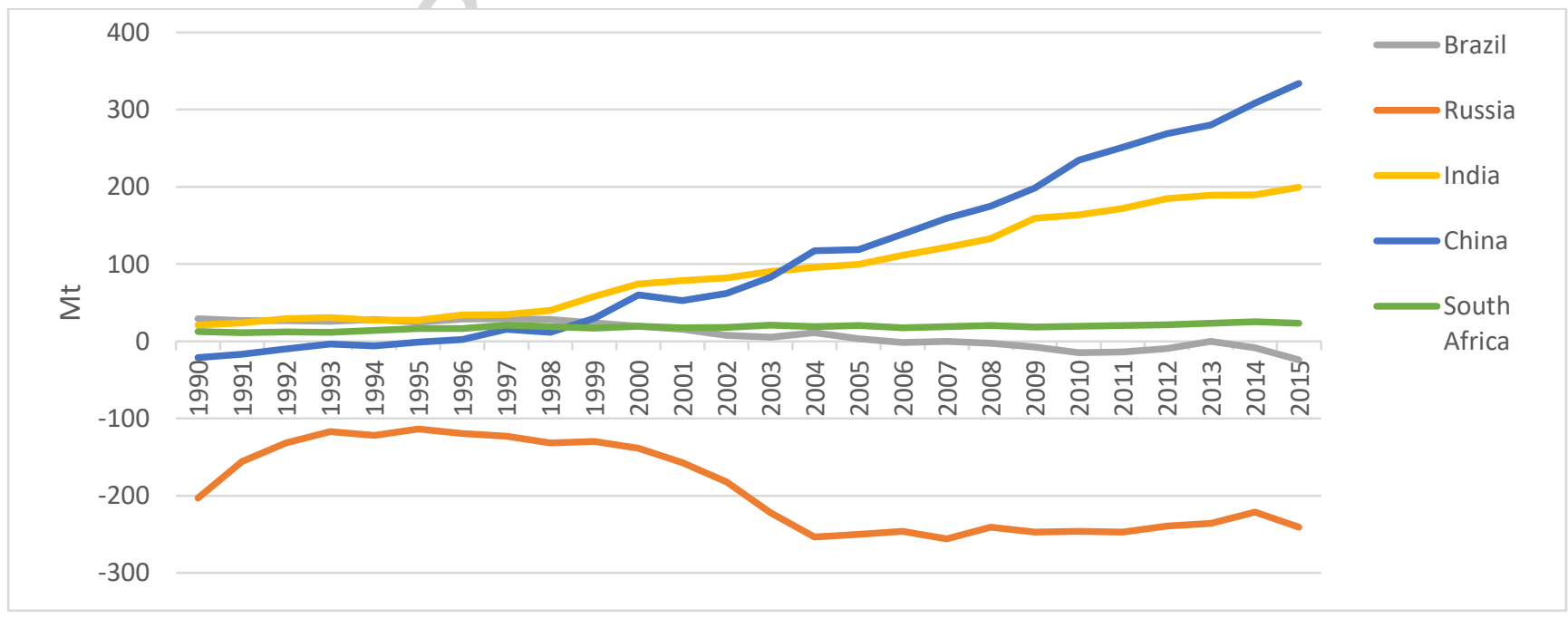

\footnotetext{
${ }^{4}$ There is a significant association between oil and economy which also have strong ecological dimensions. See e.g. Kallis and Sager (2017) for the interesting insight on the oil \& economy nexus through the lens of ecological economists

${ }^{5}$ See pie charts of with Breakdown of 10 major imports and exports of BRICS economies.
} 


\section{Figure-1: Crude Oil Balance of Trade 1990 - 2015, Source; Enerdata (2016)}

The positive values imply excessive demands and hence deficit in the trade balance of crude oil and vice versa. As it suggests, there has been a consistent increase in the demand for oil by emerging economies of Indian and China, in fact in 2015, China imported as much crude oil as the United States (Enerdata, 2016). On the consumption of oil and its association with economic growth, the evidence suggests that oil consumption is the main driver behind the progress of industrialization and urbanization (Halkos et al. 2011). Concomitantly, it is prima facia evident that fuel and petroleum are the major imports as well as exports of the BRICS economies. The empirical evidence suggests that volatility in oil prices have a different impact on an oil-exporting economy to that of an oil-importing economy's trade balances (Kilian et al. 2011). Perhaps, being an exporter, it is important for the exporting countries as it affects their income, while for importing countries it may raise the cost of production and act as a negative supply-side shock. Since the Global Oil Shock in the 1970s, studies on the macroeconomic dynamics have argued that the fluctuation of oil prices is an important factor that contributes to economic fluctuations and the essence of a global shock that is likely to affect many economies whether it is oil-importing or oil exporting. On the external balance of an economy, the impact of the volatility of oil prices on trade balances have been the focus of investigations, though often directed at industrialised countries (Rotemberg and Woodford 1996, Bollino 2007, Kilian et al. 2009, Ozlale and Pekkurnaz 2010, Bodenstein et al. 2011, Le and Chang 2013). With the rapid globalisation and free trade, the effect of volatility of oil prices shall not be gigantic if cushioned for oil-importing and oil-exporting countries. However, it has been argued that this was not the case, the volatility in oil prices are said to have a different impact on an oil-exporting economy to that of an oil-importing economy's trade balances (Kilian et al. 2011). Differences on the impact of low oil prices on trade balance of an oil-importing country to that of an oil-exporting country is expected, the impact of positive and negative oil shocks on macroeconomic variables differs both in the way and extents (Narayan and Sharma 2011, Cashin et al. 2014).

Nevertheless, the dependence on trade or openness of an economy is a major reliance point as it can improve economic efficiency through the correct utilisation of resources and on the other hand, it could result in a trade deficit and in turn slow down economic growth. It could be the case for the BRICS where a member like Russia relies heavily on oil exports and China and India due to its vast economic reforms, relies heavily on oil imports as its input for production processes. This heavy reliance on oil, being either an exporter or importer, entails 
potential implications beyond trade balance to the domestic economy. As such, on internal balance of an economy i.e. inflation and output, a number of studies have investigated the impact of oil shocks on domestic economy (see Hamilton 2005, Barsky and Kilian 2004, Backus and Crucini 2000, Kilian et al. 2009, Kallis and Sager 2017, a detailed discussion in next section) and documented that macroeconomic variables like inflation and economic growth that are most likely to be affected by the volatility of oil prices whether it is an oil importing or an oil exporting country. Considering a hike in oil prices as a negative supply shock, it has been demonstrated that there is an adverse impact on the global economy and most of the increase in oil prices preceded almost every recession that has happened since 1965 (Tang et al. 2010). However, the recent decrease in the world oil prices from the second quarter of 2014 to the beginning of 2016 (a slump of over $70 \%{ }^{6}$ in price) did not turn out to be a positive supply shock which could have led to a significant growth in global economy (FRED, 2017). This is prima facie evidence that the positive supply shock could also have negative demand implications.

The following is an account of the differences in the way BRICS are affected as oil shocks hit their respective economies. The BRICS are chosen due to the importance of this block in the global economy, furthermore, this is also an interesting block in a sense that two of its members Brazil and Russia are exporters of oil while India, China and South Africa are net importers. Nevertheless, an important point we shall emphasise here (also evident in Figure1) that there has been a huge increase in the demand for oil in India and China, which may also have time-varying effects on the nexus between oil prices shocks and internal \& external balances of BRICS countries. These factors are the main motivation and provide rationale for the subject study. Concomitantly, the intention of this study to determine the impact of oil prices on internal balances i.e. GPD and inflation and external balances (balance of trade) of BRICS. To facilitate this endeavour, we employed a Time-Varying Structural Vector Autoregression (TV-SVAR) framework on the data from 1987QII to 2017QII. Our key findings suggest that there are substantial heterogeneities in the response of BRICS economies to oil shocks. Comparative analysis brought home to us that the said differences were, in fact, profound between and even within oil exporters and importers. Specifically, it showed that between the major oil exporters i.e. Russia and Brazil, the former's economy was rather more intensively influenced by oil price shocks. On the other hand, the

\footnotetext{
${ }^{6}$ The Crude Oil Prices (Brent) fell from its peak from over US\$ 115 in June 2014 to around US\$27 per barrel in January 2016 (FRED, 2017).
} 
comparison between the two largest net oil importers i.e. India and China suggested that the Indian economy seemed to rather more vulnerable to oil price shocks in terms of their adverse effects on GDP, inflation and balance of trade. The analysis on South Africa also showed a negative impact of oil price shocks, however, the effects are comparatively more time-variant than other BRICS members.

The remainder of this paper proceeds as follows: Section- 2 provides a brief review of the literature and existing evidence related to the subject, in Section-3, we will set out a TVSVAR framework as a means to analyse the association among variables of interest and Section-4 will report the empirical results which will lead to a conclusion in Section-5.

\section{$2 \quad$ Literature Review}

\subsection{Oil Shocks and Economy}

Since its discovery, oil being an essential element, directly associated with production process has notable effects on inflation and output. The spark of interest to study the impact of oil prices on the economy arose in the 1970's following two conjointly episodes of oil shocks (Rafiq et al. 2016). On this aspect, pioneer work by Hamilton (1983) suggested that oil prices shocks have substantially contributed to the economic contractions in the U.S. In succeeding contributions, Hamilton $(1988,1996)$ further emphasised the relationship between recessions and oil shocks. Drawing on the foundation laid by Hamilton, a number of studies dug further into this line of inquiry and extended our insight on the impact of oil prices on production and output (Rafiq et al. 2016). Besides income and production, oil prices can also have an effect on other aspects of an economy such as inflation, interest rate, exchange rate and stock prices (Kilian and Vigfusson 2011, Kilian and Vigfusson, 2011b, Kallis and Sager 2017). However, in specific to this study we are focused on inflation, GDP and balance of trade of the BRICS economies in the face of oil shocks ${ }^{7}$.

\subsection{Oil Shocks and Internal Balance}

In terms of internal balance or domestic macroeconomic outlook, the volatility in oil prices has been perceived to often have a negative impact on the aggregate economy. An increase in oil price leads to an increase in the overall price level and a decrease in output. Furthermore, a rise in oil prices has a negative impact on commodity prices which results in a reduction in

\footnotetext{
${ }^{7}$ The inflation and GDP can be seen as the internal balance between the growth and price level and the balance of trade as external balance of the BRICS economies.
} 
aggregate demand (Dornbursch et al. 2001). The macroeconomic effects of oil shocks are transmitted mainly via demand and supply-side channels. In terms of a supply channel, as the crude oil is used as an input in the industrial production processes, an increase in oil prices can increase the marginal cost of production thus decreasing the company's capacity utilisation which then leads to a decrease in output and employment (Tang et al. 2010). Nevertheless, the fluctuations in oil prices may cause a decrease in investment and if there is a persistence of high oil prices then the capacity of future production may experience a reduction. Concomitantly, the volatility of oil prices is of concern as investors could also become very sceptical and postpone investments (Verleger 1994, Hamilton 1996). Therefore, Hamilton (1996) argued that an increase in oil prices will cause a structural shift in oilintensive industries as their production will be limited, whereas non-oil dependent industries are likely to benefit and will increase their production processes. The demand side channel is closely related to the supply side channel when there is a rise in oil prices, production processes are reduced and the overall price level is increased. The increase in the overall prices translates to the decrease in purchasing power of money and an increase in living costs (Jimenez- Rodriguez and Sanchez, 2005). Furthermore, there is a transfer of income and resources that follow, it is mainly from oil-importing countries to oil-exporting countries which are more likely to decrease the global aggregate demand (Tang et al. 2009). An important point to emphasise here is the symmetry of transmission mechanism in oil exporting and importing countries, given that the subject economies of BRICS are different in their size, structure, oil production and consumption, it is very intuitive that their domestic economies (and trade balance) may respond differently to oil shocks.

The nexus between oil prices shocks and inflation have macroeconomic policy implications, a cost-push oil shock may lead the monetary authorities to take a tightening stance. Hence, to strike the right balance between inflation and output (maintain the internal balance), interest rates may rise influencing the aggregate demand in the economy (see Ferderer 1996, Hunt et al. 2001). Basing our reasoning on the same logic, it is will be fair to argue that if the transmission mechanism of oil prices shocks in the different BRICS economies vary, the policy responses shall vary too. The BRICS includes two of the largest economies in the world, China and India, which have been growing rapidly leading to an increase in household expenditures, the demand for primary energy consumption has increased enormously which has therefore left a big gap between oil production and its consumption, leaving it no other choice but large-scale imports. There have been episodes of rapid increase in oil prices which 
have caused concerns about the global growth, however, the effects could vary country by country due to their difference in economic structure, energy consumption and dependence on the international energy market ( $\mathrm{Wu}$ et al. 2010). The existing limited evidence on the BRICS economies is analysis of individual countries, for instance, Tang et al. (2010) on China reported negative impact of oil prices hikes on output, investment and positive impact on inflation, while on Russia, Rautava (2004) and Kuboniwa (2014) reported positive, but contrarily, studies, for instance, Benedictow et al. (2013), Dülger et al. (2013) and Mironov and Petronevich (2015) reported negative effects. They argued that as the energy prices increase, appreciation of the rubble can have harmful effects (Dutch disease), nevertheless, there could also be substitution and income effects for non-oil producers and consumers. A study by Idrisov et al. (2015) suggested that in fact, the impact of oil prices changes on Russian economy has actually decreased. While, a recent study on Russia, in the light of recent sanctions on Ukraine issue, Dreger et al. (2016) showed a very strong association between oil prices and the Russian economy (interest rate and exchange rate). Given that we consider the BRICS as a block, an holistic analysis of this block is feasible. It is intuitive to expect some asymmetries in the response of these economies to oil shocks. Perhaps, awareness of them can then lead to provide a context in which further cooperation can be extended. Nevertheless, the structure of these economies has seen substantial shifts leading to increasing energy appetite which could also have implications for external balance.

\subsection{Oil Shocks and External Balance}

Oil prices can impact trade balances of countries, firstly through the terms of trade and secondly via wealth effects (Amano and Van Norden, 1998). It is intuitive to expect some heterogeneity in the response of the external position of different economies to oil price shocks, contingent on their economic structure and net trade position in oil. The imbalances in the current account position can occur through different channels, however, we will concentrate on two particular channels which are trade and financial channels as they are much more pertinent to the theme of this treatise. Through the trade channel if there is an increase in oil prices then its effect decreases real income in oil-importing economies which then, in turn, deteriorate the terms of trade. As a consequence of the fall in real income in importing countries, domestic consumption will be reduced as well as investment, furthermore, oil-importing countries' will depreciate and oil-exporting countries' currency may appreciate (Kilian et al. 2007). The rippling effect will cause a decrease in real output for oil-importing countries at least in the short-run. As for the financial channel, if there is a 
decrease in the asset prices and dividends in oil-importing countries due to an increase in oil prices, then all the asset owners will be affected but the asset prices in oil exporters will increase, which will as well affect all asset owners resulting in a temporary imbalance in the current account of oil-importing and oil-exporting countries. However, keeping the transmission channels in context, the point requires emphasis is that most theoretical models that have been used to demonstrate the effect of oil prices fluctuations on the economy (most importantly on the external accounts) have been constructed in a time-invariant fashion and oil prices have been treated as an exogenous factor compared to the whole economy (Kilian et al. 2007, Bodenstein et al. 2011). Moreover, it has been argued that there is concrete empirical evidence demonstrating that the global macroeconomic fluctuations have an impact on the prices of oil, with oil prices fluctuations, the booming global business cycle expansion has been said to be the cause of the rapid increase in the prices of oil. However, the same economic shocks that impact the external accounts also impact the prices of crude oil making it difficult to differentiate between the cause and effect of the increase in oil prices on external accounts.

There are differences in the way how oil prices affect trade balances due to oil supply and demand shocks and also there are differences in the way, oil shocks have impact on the importers and exporters (Kilian et al. 2009, Le and Chang 2013, Rafiq et al. 2016). According to Rodriguez and Sanchez (2005), the volatility in oil prices affects the supply and demand side of real economic activities. Furthermore, an increase in oil prices will result in an increase in production costs which would then decrease the level of supply, decrease income on investment and decrease investment demands which then, in turn, affect trade. On the impact of oil prices shocks, it has been often suggested that the impact of high oil prices on the trade balance of an oil-exporting country is positive (Rafiq et al. 2016). However, Le and Chang (2013) pointed out that an increase in oil prices is not all positive, with an increase in oil prices, pressure is exerted on the inflation in global markets making imports more expensive for oil-importing and oil-exporting countries ${ }^{8}$. Furthermore, the demand for oil will decrease which will affect the trade balance of an oil-exporting country (demand effect) and also an increase in oil prices will have a negative effect on oil-importing countries, as it will slow down their production processes and imports which will then again affect the trade

\footnotetext{
${ }^{8}$ As discussed earlier, as the result of the inflation, monetary authorities would have to increase the interest rates to curb the inflation which would then lead to a decrease in consumption and investment resulting in an economic slowdown (Ferderer, 1996).
} 
balance of an oil-exporting country (supply effect). Based on this notion, it can be argued that an oil exporter's gain from an increase in oil prices relies heavily on the interdependencies of the revenues, demand and supply effects (Le and Chang 2013, Cashin et al. 2014). Moreover, even if there is an overall positive impact from the increase in oil prices for the oil-exporting country, there are counteracting negative concerns such as the Dutch disease and dependency on trading partners.

As for oil-importing countries, some studies have documented the negative effect of the increase in oil prices on their terms of trade (Kim and Loungani, 1992). But, Kilian (2010) argued that the cost share effect needs to be taken into consideration, the negative cost shock might not be as big as it seems and the cost share of oil might be small in oil-importing countries' production process (in this study it could be South Africa or smaller exporter Brazil, refer to Figure-1). Furthermore, there are other types of energy sources and it might not be a problem for oil-importing countries to decrease their cost share of oil in the production process locally and also, oil importing countries can counteract the adverse effect of increasing oil prices by increasing the exports of other non-oil products to the oil-exporting trading partners and so improving their trade position. Hence, it can be inferred that as oilexporting countries, the effect of positive oil prices shocks on oil importing countries can be determined by taking account of all these effects. The effect of low oil prices on the trade balance of oil-exporting countries has been documented to have two types of effect one being negative, which is the revenue effect, with low oil prices, income decreases, however the second effect is a positive one, as when oil prices decrease, there is an increase in demand from oil-importing countries known as the demand effect (Kilian, 2010). As for the movement of free trade sweeping the world, a decrease in oil prices could very well benefit oil exporters as their terms of trade will ameliorate with the increase in demand, but there is also a negative consequence, with low oil prices oil importers will tend to increase their oil imports thus putting pressure on their external balances. Concomitantly, only an analysis of aggregate net trade balances can suggest the net implications of oil shocks.

The trade balances are of much importance to global economic stability, the matter of concern is that through the increase or decrease in global oil prices, huge trade imbalances have been created for oil-importing and oil-exporting countries, much aggressively impacted oil-importing countries. On this issue, Fratzscher et al. (2014) argued that an increase in oil prices could lead to a trade imbalance in oil-importing countries because oil-intensive 
products become more expensive and therefore the depreciation of the country's currency can cushion the effect of the imbalances in the shorter term but in the longer term, the extent of the impact will have to be eradicated by the use of different policies. However, Buetzer et al. (2012) argue that for oil-exporting countries, a rise in oil prices could potentially lead to the Dutch Disease's phenomenon, meaning the prices of the non-tradable goods will increase and the appreciation of their currency which then leads to their exports becoming more expensive. In order to demonstrate this phenomenon, Lizardo and Mollick (2010) using the US as an example, conclude that an increase in oil prices caused its currency to depreciate against the currencies of oil exporters like Canada, Mexico and Russia. On Russia, empirical studies have documented a varying decrease of impact on trade balance and economy (contrast Rautava 2004, Ito 2010, Kuboniwa 2014, Dreger et al. 2016). Among other studies in similar dimension, Raguindin and Reyes (2005) on the Philippines, Wakeford (2006) on South Africa and Gounder and Bartleet (2007) on New Zealand have reported negative effects of oil price shocks on trade balances. Interestingly, on China, Lai (2004), Thai-Ha (2010) and Wu et al. (2012) argued that oil prices shocks are not of much concern for China as it has amassed huge surpluses, maintained a stable currency and growth. Nevertheless, Qianqian (2011) reported that the effects on the Chinese trade balance are only short term. This is an interesting line of argument, perhaps, having large trade surpluses in the face of oil price shocks due to the strong exporting sector does not imply that oil shocks will have no effects. Perhaps, counterfactually China could have amassed even greater surpluses. In fact, a rather recent, study by Wei and Guo (2016) reported stronger effects of oil prices on exports of the Chinese state-owned enterprises. This then implies a case of time varying response of the Chinese economy and perhaps, other BRICS member's external position to oil shocks. Nonetheless, being an exporter shall not universally infer a positive implication of oil shocks for the economy, a comparative study by Kuboniwa (2014) on oil-rich economies of the Pacific-Rim including Russia, Malaysia and Indonesia reported that oil prices have a positive impact on terms of trade in Russia and Malaysia, however, in case of Indonesia the impact was negative. Similarly, Wang et al. (2013) significant difference in the impact of oil prices shocks on oil importing and exporting countries as well as differences in terms of oil dependency. Concomitantly, it may have various heterogeneities in the responses of oil exporters and importers among BRICS members. Keeping that in context, this study is an endeavour to analyse the impact of oil prices shocks on the BRICS economies in a TV-SVAR framework, details follow in the next section. 


\section{Methodology and Data}

\subsection{Methodology}

We use a Time-Varying Structural Vector Auto-Regressive (TV-SVAR) model to analysis the impact of oil prices shocks on inflation, GDP and trade balances of BRICS region. Our framework drew on the foundations laid in seminal work by Primiceri (2005) and Del Negro and Primiceri $(2015)^{9}$. There are a number of studies which contributed to the development of time-varying modelling. For instance, Canova (1993), Sims (1993), Stock and Watson (1996) and Cogley and Sargent (2001) made remarkable contributions to the estimation of VAR frameworks in which they used drifting coefficients, on the other hand, studies, like Harvey et al. (1994), Kim et al. (1998) and Chib et al. (2002) promoted the notion of multivariate stochastic volatility into models ${ }^{10}$. However, there were two caveats in these frameworks a) the simultaneous relation in the under analysis variables in their models were time invariant, b) their analysis was limited to the reduced form models with feasibility only for descriptive analysis of data for forecasting purposes. However, this study employs the TV-SVAR framework, where, coefficients and entire variance-covariance matrix of the shocks are allowed to vary over time. This is crucial if the objective is distinguishing between changes in typical size of the exogenous innovations and changes in the transmission mechanism of oil prices shocks (Primiceri, 2005). Often in the time variation frameworks, discrete breaks are included to cater for the limited number of switching regimes (for instance, see Sims 1999, Sims and Zha 2006). The discrete break model is feasible to consider the rapid shift in the under analysis entities, however, it seems less suitable to capture behaviour of macroeconomic aggregates and market participants in response to oil prices shocks, particularly, in a scenario where aggregation among agents usually plays the role of smoothing most of the changes (See Primiceri, 2005 for details discussion). Concomitantly, in this treatise, the dynamics of macroeconomic aggregates and oil prices shocks favours a model with smooth and continuous drifting coefficients and heteroscedasticity innovations over a model with discrete breaks.

\footnotetext{
${ }^{9}$ Please see Primiceri (2005) for an interesting insight into the development of TVSVAR framework.

${ }^{10}$ With all the regards to novelty of their framework, they did imposed some restrictions on the evolution over time of the elements of the variance-covariance matrix. Their typical restriction was that the covariances do not evolve independently of the variances or a factor structure for the covariance matrix. Among other remarkable efforts, Boivin (2001) considered the case of time varying simultaneous relations but did not address the potential heteroscedasticity of the innovations. Later, Ciccarelli and Rebucci (2003) extend the framework of Boivin (2001) allowing for t-distributed errors, which account for non-persistent changes in the scale of the variances over time. Although, by Uhlig (1997) introduced unrestricted multivariate stochastic volatility in the context of VARs, his model assumed that the VAR coefficients are constant.
} 


\subsection{TS-VAR Model}

Considering the fact that the TV-SVAR model employed in this study occasions the properties of time-variation in coefficients and variance-covariance matrix of the additive innovations, concomitantly, it is beneficial as the drifting coefficients capture the possible nonlinearities or time-variation in the lag structure of the model. Nevertheless, the multivariate stochastic volatility captures the possible heteroscedasticity of the shocks and nonlinearities in the simultaneous relations among the variables of interest. Therefore, it is the data employed which determines if the time variation of the linear structure derives from changes in the size of the shocks (impulse) or from changes in the propagation mechanism (response). Let's starts by considering the following model: -

$$
y_{t}=C_{t}+B_{1, t} y_{t-1}+\ldots \ldots \ldots+B_{k, t-k}+u_{t} \quad \mathrm{t}=1, \ldots \ldots \ldots, \mathrm{T} .
$$

where $y_{t}$ is an $\mathrm{n} x 1$ vector of observed endogenous variables; in specific to subject study, these will be GDP growth, inflation and trade balance; $C_{t}$ is an $\mathrm{n} x 1$ vector of time varying coefficients that multiply constant terms; $B_{i, t, i=1, \ldots, k}$ are the $\mathrm{n} \times \mathrm{n}$ matrices of time varying coefficients; $u_{t}$ are heteroscedastic unobservable shocks with variance covariance matix $\Omega_{t}$ defined by

$$
A_{t} \Omega_{t} A_{t}^{\prime}=\sum_{t} \sum_{t}^{\prime}
$$

where $A_{t}$ is the lower triangular matrix,

$$
A_{t}=\left[\begin{array}{ccccc}
1 & 0 & \ldots & \ldots & 0 \\
a_{10} & 1 & \ddots & \ddots & \vdots \\
\vdots & \ddots & \ddots & \ddots & 0 \\
a_{n 1, t} & \ldots & \ldots & a_{n n-1, t} & 1
\end{array}\right]
$$

and $\sum_{t}$ is the diagonal matrix

$$
\sum_{t}=\left[\begin{array}{ccccc}
\sigma_{1, t} & 0 & \ldots & \ldots & 0 \\
0 & \sigma_{2, t} & \ddots & \ddots & \vdots \\
\vdots & \ddots & \ddots & \ddots & 0 \\
0 & \ldots & \ldots & 0 & \sigma_{n, t}
\end{array}\right]
$$

Thus, it follows that

$$
y_{t}=C_{t}+B_{1, t} y_{t-1}+\ldots \ldots \ldots . .+B_{k, t-k}+A_{t}^{-1} \sum_{t} \varepsilon_{t}
$$




$$
V\left(\varepsilon_{t}\right)=I_{n}
$$

Stacking in a vector $B_{t}$ all the right hand side coefficients in equation-3 could be rephrased as:

$$
\begin{aligned}
& y_{t}=X_{t}^{\prime} B_{t}+A_{t}^{-1} \sum_{t} \varepsilon_{t} \\
& X_{t}^{\prime}=I_{n} \otimes\left[1, y_{t-1}^{\prime}, \ldots, y_{t-k}^{\prime}\right]
\end{aligned}
$$

where the symbol $\otimes$ represents the Kronecker product. The decomposition of variancecovariance matrix as presented in equation- 4 is appropriate particularly when one is focused on efficiently estimating covariance matrices (see Smith and Kohn 2002, Primiceri 2005). A fairly similar decomposition was carried out by Cogley (2003) and Cogley and Sargent (2003) employing a Time-Varying VAR models, however, with a time-invariant $A_{t}$ matrix. As we have discussed that earlier, it is vital that to allow the matrix $A_{t}$ to be time-variant for the true spirit of a TV-SVAR framework. Keeping the $A_{t}$ constant would imply that an innovation to the $i-t h$ variable has a time-invariant effect on the $j-t h$ variable which is definitely inappropriate if we are aiming to model the time-variation in a simultaneous equation model, particularly, where simultaneous interactions among variables are fundamental as in this study ${ }^{11}$.

At this juncture, if we let the $a_{t}$ be the vector of non-zero and non-one elements of the matrix $A_{t}$ and $\sigma_{t}$ be the vector of the diagonal element s of the matrix $\sum_{t}$. The dynamics of our model's time-varying parameter can be specified in the following fashion:

$$
\begin{aligned}
& B_{t}=B_{t-1}+v_{t}, \\
& a_{t}=a_{t-1}+\zeta_{t}, \\
& \log \sigma_{t}=\log \sigma_{t-1}+\eta_{t},
\end{aligned}
$$

\footnotetext{
${ }^{11}$ The modelling strategy entails modelling the coefficient process in (4) and one to one mapping from equation 1 to 4 provides justification to this approach.
} 
where the components of the vector $B_{t}$ are modeled as the free elements of the matrix $A_{t}{ }^{12}$ as well as random walk. Although the random walk process might be considered undesirable here due to the general perception that that it hits any upper or lower bound with the probability 1 . However, as long as $(5-7)$ are placed for a finite period of time this set of assumption would be fairly innocuous. Nevertheless, the assumption of random walk comes with the benefit of reduced number of parameters as well as provides focus on permanent shifts (Primiceri, 2005). With the following assumptions on the variance covariance matrix, all the innovations in the model are assumed to be jointly normally distributed:

$$
V=\operatorname{Var}=\left(\left[\begin{array}{c}
\varepsilon_{t} \\
v_{t} \\
\zeta_{t} \\
\eta_{t}
\end{array}\right]\right)=\left[\begin{array}{cccc}
I_{n} & 0 & 0 & 0 \\
0 & Q & 0 & 0 \\
0 & 0 & S & 0 \\
0 & 0 & 0 & W
\end{array}\right]
$$

where $I_{n}$ is a n n-dimensional identity matrix, $Q, S$ and $W$ are positive definite matrices ${ }^{13}$. The coefficients of the simultaneous associations among variables of interest are supposed to evolve independently in each equation, despite that this is not the fundamental assumption, yet it is beneficial due to the increases the efficiency of the estimation algorithm and it simplifies the inference.

\subsection{Bayesian Estimation}

The Bayesian approach is chosen for estimation and evaluation of posterior distribution of the parameters of interest, in specific to the subject case these are $B^{T} A^{T} \Sigma^{T}$ and the hyperparameters of the variance covariance matix $V$. The Bayesian approach is appropriate, particularly in scenario like this where the distinction between parameters and shocks is less clear while we are dealing with unobservable components ${ }^{14}$. The Gibbs Sampling is

\footnotetext{
12 Supposedly, the standard deviations $\sigma_{t}$ are to evolve as geometric random walks and classed as stochastic volatility, it can be considered as an alternative approach to the $\mathrm{ARCH}$ with the crucial difference that the variances generated are unobservable component. On this aspect Shepherd (1996) provided a good overview and comparative analysis of stochastic volatility models with $\mathrm{ARCH}$.

${ }^{13}$ Note: There isn't any restrictions imposed on the structure of $\mathrm{V}$ which is essential as all the zero blocks could be substituted by non-zero blocks, it will require only minor alteration to the estimation procedure. Furthermore, there are two important reasons for which we choose $\mathrm{V}$ as the one specified in the equation (8). Firstly, we have high number of parameters of the model; hence, adding all the off diagonal elements of $\mathrm{V}$ would require the specification of a sensible prior, able to prevent cases of ill-determined parameters. Secondly, catering for a completely generic correlation structure among different sources of uncertainty would preclude any structural interpretation of the innovations.

${ }^{14}$ Furthermore, Bayesian approached is preferred over the Classical estimation approach to estimate subject class models because a) if the variance of the time varying coefficients is small, the classical maximum likelihood estimator of this variance has a point mass at zero, related to the commonly called pile-up problem b)
} 
employed for the posterior numerical evaluation of the parameters of interest which is a particular variant of the Markov Chain Monte Carlo (MCMC) approach that consists of drawing from lower dimensional conditional posteriors as opposed to the high dimensional joint posterior of the whole parameter set. The MCMC is a smoothing method and therefore leads to obtain smoothed estimates i.e. parameter estimates of the parameters based on the entire set of data available to us. In specific to this study where we are analysing the implications of oil prices shocks for the true evolutions of internal and external balances, the smoothed estimates seems to be more efficient (See Primiceri, 2005) ${ }^{15}$. The filtered estimates as one might have suggested would have not been appropriate in our analysis due transient variation they exhibit even when employing a time invariant framework (Sims, 2001).

\subsection{Prior Selection}

The selection of prior distributions is based on their appropriateness and applicability. To start with, the assumption that the hyperparameters are independent of each other and the initial states of the coefficients, for the covariances, for the log volatilities is legitimately initiative. The priors for the hyperparameters, $Q, W$ and the blocks of $\mathrm{S}$, are assumed to be distributed as independent inverse-Wishart. Whereas, the priors for the initial states of the time varying coefficients, simultaneous relations and log standard errors $p\left(B_{0}\right), p\left(a_{0}\right)$, and $p\left(\log _{\sigma 0}\right)$, are assumed to be normally distributed. These assumptions together with (5), (6) and (7) imply normal priors on the entire sequences of the B's, $\alpha$ 's and log $\sigma$ 's (conditional on $\mathrm{Q}, \mathrm{W}$ and $\mathrm{S}$ ). The use of normal priors is fairly standard and also not being conjugate they have advantage in terms of tractability (See, Smith and Kohn 2002, Sims and Zha 1998, and Primiceri, 2005). As mentioned earlier, the MCMC algorithm is used to generate a sample from the joint posterior of $B^{T} A^{T} \Sigma^{T}$ and $V$. The Gibbs sampling is used in order to exploit the blocking structure of the unknowns and it is performed in four steps, i) drawing in turn time varying coefficients $B^{T}$, ii) simultaneous relations $A^{T}$, iii) volatilities $\Sigma^{T}$ and iv)

Secondly, classical maximum likelihood is related to the high dimensionality and nonlinearity of the problem which is a problem as such a complicated model often has a likelihood with multiple peaks, some of which not much of interest or in the region of the parameter space which is not plausible. Furthermore, in case these peaks are very narrow, the likelihood may reach particularly high values, not at all representative of the model's fit on a wider and more interesting parameter region. Interestingly, in Bayesian framework, the use of uninformative priors on reasonable regions of the parameter space is effective in ruling out such misbehaviours C) the practicality of approach, writing up of the likelihood of the model is possible (at least in principle) yet, it is very difficult to maximize it over a very high dimensional space. Whereas, Bayesian approach very efficiently deals with the high dimension of the parameter space and the nonlinearities in the model, splitting the original estimation problem into smaller and simpler ones. Concomitantly, Bayesian seems the appropriate approach to consider.

${ }^{15}$ The Strategy of considering the whole sample and then discrete break has an innovative aspect and will give us further insight into the under analysis relationship in two different ways. 
hyperparameters $V$, conditional on the underlying observed data and the rest of the parameters $^{16}$. The empirical framework layout above is applied on the dataset of BRICS economies.

\subsection{Dataset}

The dataset includes the series on macroeconomic variables which are inflation and economic growth to present internal balance and balance of trade to present the external balance respectively. The data on oil prices are also included. The overall period of analysis is from 1987QII - 2017QII, however, depending on the availability of data, the period of analysis in each BRICS member country varied. We have quarterly observations on Brazil (1997QI2016QIV), Russia (1997QI- 2017QII), India (1997QI - 2016QI), China (1998QI - 2017QII) and South Africa (1987QII-2016QIV). The choice of the period was contingent on the availability of data. In terms of proxies, for economic growth, we used the quarterly data on real GDP growth rate year on year percentage change. To proxy inflation, we used the monthly data on consumer price index, year on year percentage change, monthly observations were converted into quarterly by averaging. The trade balance as a percentage of GDP was used as a proxy for balance of trade in all the countries except Russia. Due to the nonavailability of this series, we used the percentage change in trade balance for Russia instead of trade balance as a percentage of GDP.

\section{Analysis and Findings}

To gain some insight into the statistical properties of the employed dataset, we conducted a couple of tests prior to application of TV-SVAR framework. It entailed a unit root test using ADF approach test with structural breaks and lag selection tests. One may argue that Bayesian approach is not dependent on the requirement of stationarity as seminal work by Sims (1989) and Fanchon and Wendel (1992) suggested that no assumption of stationarity is required to be imposed under the Bayesian framework. However, doing so gave us some insight into the statistical properties of data and the presence of high nonlinearities. It suggested two as the optimal numbers of lags ${ }^{17}{ }^{18}$. Thereafter we proceed with TV-SVAR application. In terms of ordering of the variables oil prices shocks are ordered last due to the

\footnotetext{
${ }^{16}$ For details on identification and structural interpretation, please see Primiceri (2005).

${ }^{17}$ To determine an appropriate lag length, we performed a lag length section test using alternative information criteria (Akaike Information Criterion, Schwarz Information Criterion, Hannan-Quinn Information Criterion). Most of the lag selection criteria unanimously suggested two as optimal numbers of lags which are then incorporated into the analysis.

${ }^{18}$ The results are not presented here to conserve the space, but are available on request.
} 
exogenous nature of oil price shocks in our model. Moreover, the identification assumption also employs that oil prices shocks affect with lags. The simultaneous interaction between GDP, inflation, trade balance and oil prices shocks is arbitrarily modelled in a lower triangular form with GDP first. It is not an identification condition but for the sake of normalisation, although the arbitrary normalisation may have the potential to make difference, however, in this setting the ordering of GDP block did not affect the results. We choose 10000 iterations of Gibbs Sampling with a burn rate of 20\% i.e. (2000 iterations). The 36 observations ( 9 years) period was chosen for the training sample. We chose the last 3 quarters of the data set available for each country to draw the impulses ${ }^{19}$. Starting from the "B" of BRICS, the results are in Figure-3:

\section{Brazil}
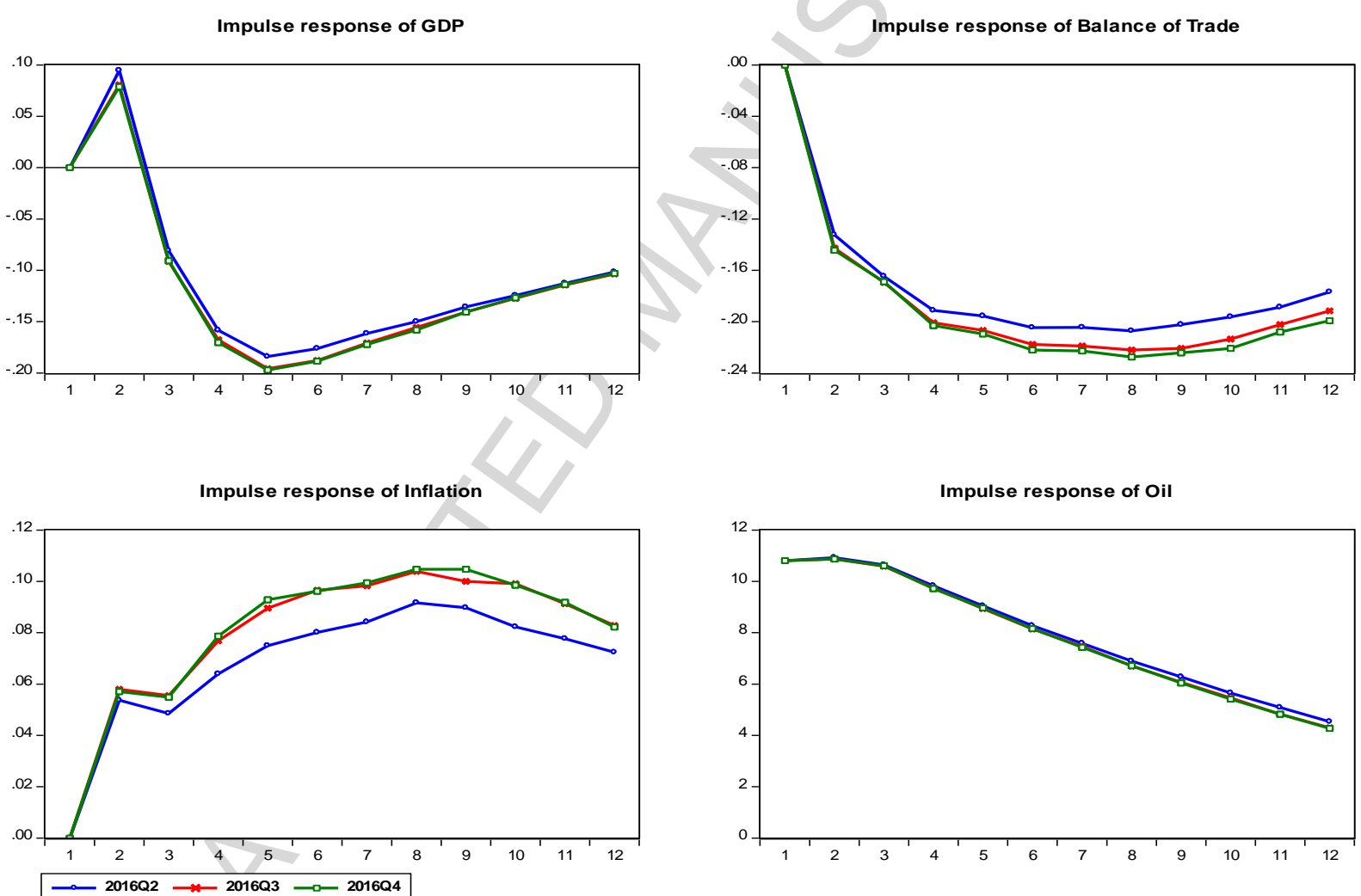

Figure-2: Impulse Response of Brazilian GDP, Inflation \& Trade Balance to Oil Shocks

The impulse responses of the Brazilian GDP showed a short-term positive response to positive oil price shocks, the effects persisted for 3 quarters of a year. Thereafter the response turned negative. The inflation also increased due to oil prices shocks and the effects of shocks

\footnotetext{
${ }^{19}$ The impulses for the individual periods are not presented here to conserve the space, but are available on request.
} 
persisted over 12 quarters. Implying only a short-term gain in terms of real GDP growth but long-term consequences in terms of high inflation. These findings are contrary to Sakashita and Yoshizaki (2016) and Cavalcanti and Jalles (2013) which could not find a clear and strong impact of oil shocks on inflation and GDP growth in Brazil. Perhaps, this is the novelty of our employed framework that we are incorporating the time-varying association among under analysis variables which gives us deeper insight. Hence, it is very intuitive that over time the importance of oil shocks has increased for Brazil. Interestingly, the balance of trade showed deterioration in response to positive oil prices shocks, which could be manifestly associated with the Dutch disease. Given that the Brazil is not the biggest exporter of oil and its economy is fairly diversified as compared to Russia, the results seemed to be very intuitive $\mathrm{e}^{20}$. Next, we come the "R" of BRICS and the results are presented as follows:

\section{Russia}
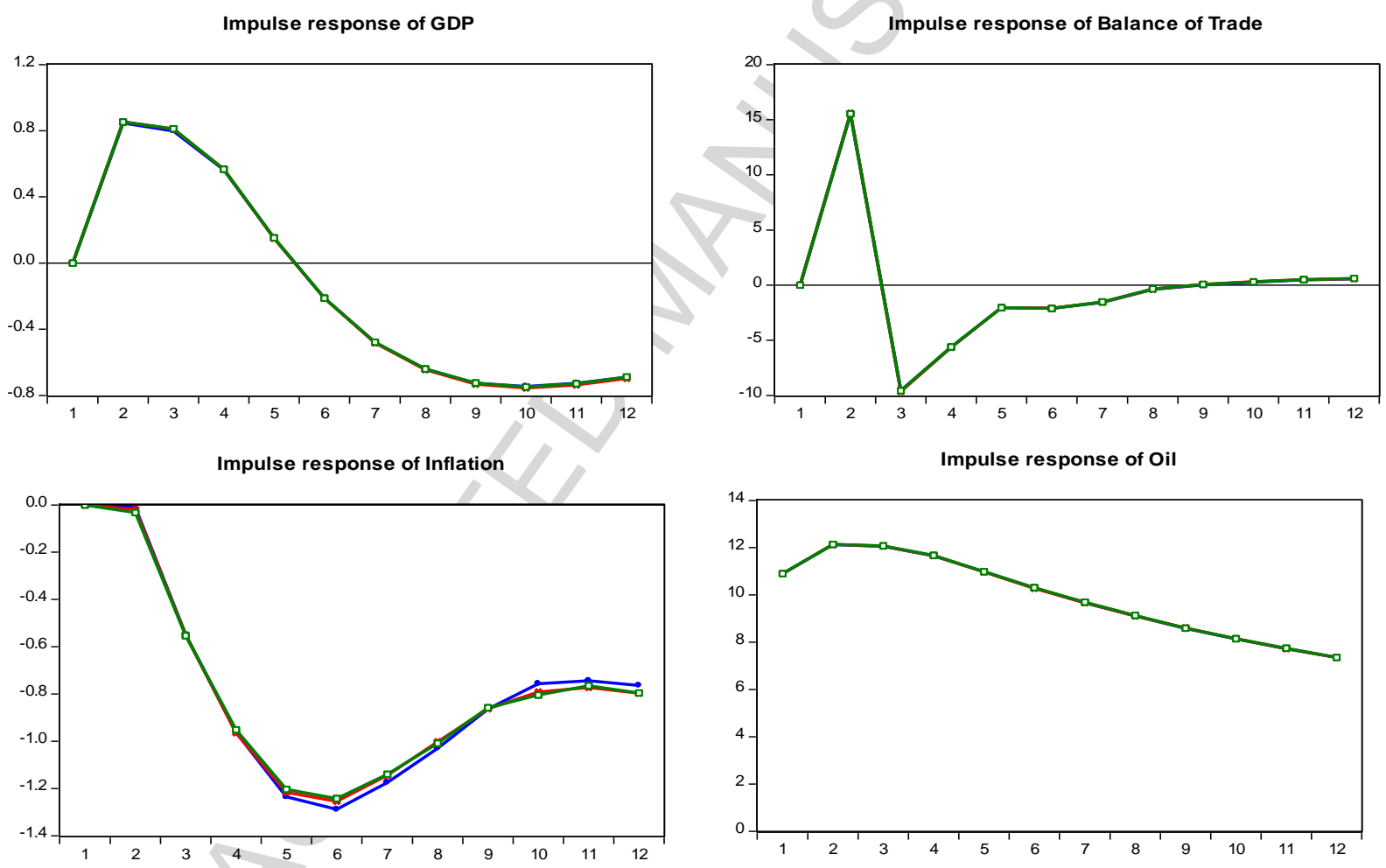

Figure-3: Impulse Response of Russian GDP, Inflation \& Trade Balance to Oil Shocks

The impulse response analysis of Russian GDP showed a positive impact of oil prices shocks on real GDP growth of the Russian economy which persisted for almost 6 quarters. This empirical evidence provides support to the assertions by Popova et al. (2017) which argued

\footnotetext{
${ }^{20}$ At the same juncture they provide a rationale to dig further in this dimension for the various channels and industries through which this nexus may prevail, that would be beyond the scope of this treatise, however, for further lines of inquiries can be opened.
} 
that the oil prices have strong effects on Russian GDP, although they did not provide any empirical support to their argument. Nonetheless, our findings are contrary to Idrisov et al. (2015) argument that the impact of oil prices shocks on Russian GDP has diminished, our findings suggest that it is not the case. Perhaps Idrisov et al. (2015) study was just theoretical analysis (DSGE simulations) without any empirical data whereas we employed the real-life data which suggests otherwise. Inflation, on the other hand, showed a negative response which also persisted for a prolonged period. The results were in line with the study by Sakashita and Yoshizaki (2016), though their results were not as highly significant as in the subject case, again it could be associated with the fact that their analysis did not account for any time variation which might have led to yielding insignificant result which are contrary to economic theory as well. Whereas our analysis clearly implies that oil prices shocks have a greater impact on Russia which is even more pronounced than effects on Brazil. In terms of inflation, the persistent negative impact is an interesting finding and could be associated with the strengthening of Russian currency with positive oil shocks as suggested by Dreger et al. (2016) which then might have led to the downward price pressure due to the pass-through channel. Hence, our findings give further insight and provide evidence of this disinflationary impact of oil price hikes for the Russian economy. On the external balance, the balance of trade showed a positive response to oil price shocks which persisted for almost 3 quarters of a year. These findings as compared to Brazil are interesting in a way that there is an obvious asymmetry in the response of Brazilian and Russian economies to oil prices shocks though both of them are oil exporters. It indicates a significant difference in the structure of these economies and role of oil. Next, we come to "I" of BRICS and the results are presented as follow:

\section{India}


Impulse response of GDP
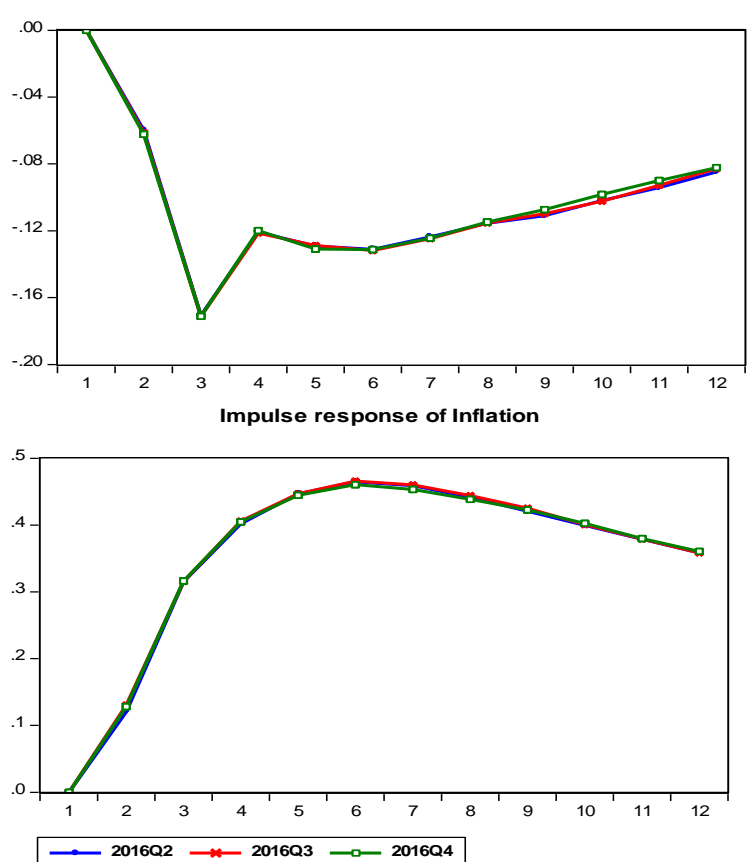

Impulse response of Balance of Trade

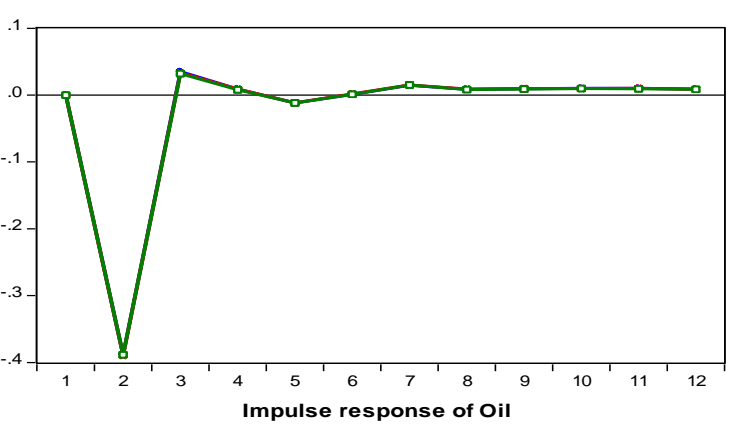

Impulse response of $\mathrm{Oi}$

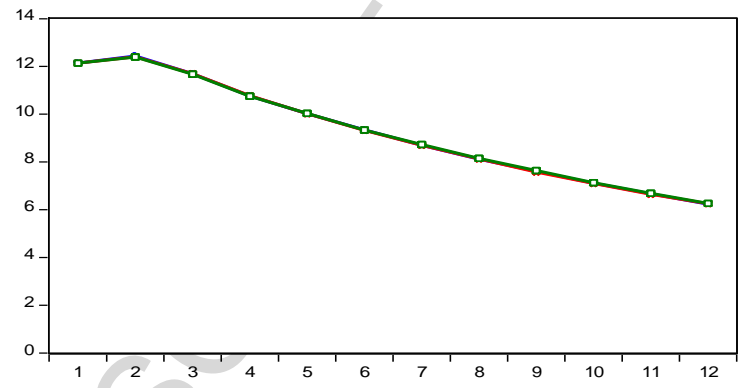

Figure-4: Impulse Response of Indian GDP, Inflation \& Trade Balance to Oil Shocks

The impulse response analysis of the Indian real GDP growth showed a negative impact of oil prices shocks which persisted for a prolonged period of time i.e. over 12 quarters. Similarly, inflation also showed a surge which persisted for an equivalent period to real GDP. It evidently implied that oil prices shocks have in fact very severe negative impact on the Indian economy's internal balance between inflation and GDP growth ${ }^{21}$. The results were contrary to Varghese (2017, page 1) assertion on the impact of oil shocks on inflation that in India "price of petroleum products are insulated against international crude oil prices fluctuations by way of subsidies in order to curb inflation" ${ }^{22}$. Perhaps, we can prima facie report a direct impact of an oil shock on inflation. Nonetheless, our findings are in line with the studies by Sakashita and Yoshizaki (2016) and Cunado et al. (2015), on the impact of oil shocks on inflation and GDP growth. Although, their results based on time-invariant SVAR were not very highly significant the impact of oil shocks was very mild. Nevertheless, the picture of external balance was also gloomy as oil shocks led to a sharp deterioration of the trade balance which persisted for 3 quarters of a year. The results on trade balance supported the argument put forward by Tiwari et al. (2014). Overall, the results implied that the Indian economy is in fact very vulnerable to oil prices shocks. Next, we come to the "C" and the largest economy of the BRICS, the results are presented as follow:

\footnotetext{
${ }^{21}$ Perhaps, in terms of policy formulation and response, it implies a difficult trade-off monetary authority (Reserve Bank of India) may face.

${ }^{22}$ Though Varghese (2017) also argued that in the long run, inflation manifest itself in the form of worsening fiscal deficit and undermine the sustainability of public debt.
} 


\section{China}
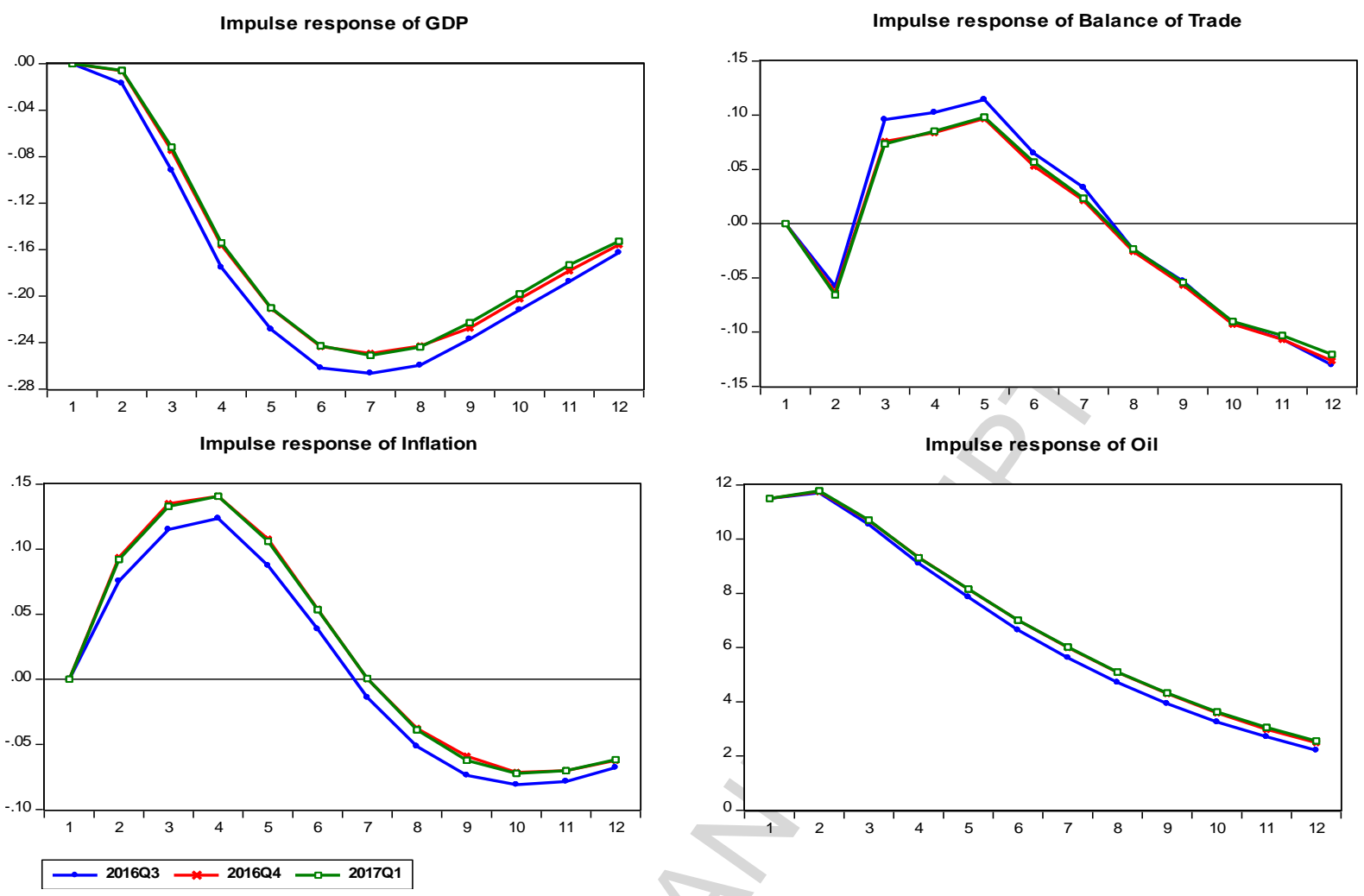

Figure-5: Impulse Response of Chinese GDP, Inflation \& Trade Balance to Oil Shocks

The impulse response of the Chinese real GDP showed a negative impact of oil prices shocks which started to materialise gradually and persisted for a prolonged period of time i.e. 12 quarters. The materialisation of the impact of oil price shocks with lags is intuitive as the hike in oil prices may take some time to feed through and appear in succeeding period's data on real GDP growth. Similarly, inflation also showed a hike in response to oil prices shock, notably, although on GDP the impact was similar to India, however on inflation, there was some dissimilarity as the effects on inflation started to fade after 7 quarters. Compared to the existing evidence, results were in line with Du et al. (2010) analysis on the impact of an oil shock on GDP, although in our case the results were more pronounced which indicates the increased importance of oil shocks for China ${ }^{23}$. Nonetheless, contrary to findings by Du et al. (2010) our results suggested an increase in inflation in response to oil shocks which is more intuitive and akin to the response of high energy consumption economy.

\footnotetext{
${ }^{23} \mathrm{Du}$ et al (2008) employed a time invariant VAR model on data from 1995-2008.Since then the Chinese economy has seen a decade a development and growth.
} 
The response of inflation was even greater than reported by and $\mathrm{Ou}$ et al. (2012) which implied increase importance of oil shocks for inflation and concomitantly implications for the monetary policy. The balance of trade also showed an initial negative response to oil price shocks which however recovered after 3 quarters. The severity of impact for the Chinese economy's external position compared with the Indian economy was, however, a lot milder, which is obviously a very intuitive finding if we consider the fact that China has a very strong trade position. Our findings on China have interesting implications if we compare them with the earlier cited argument by Lai (2004), Thai-Ha (2010) and Wu et al. (2012) which argued that oil prices shocks are not of much concern for China as it has amassed huge surpluses, maintained a stable currency and growth. Our analysis suggests that even if China has maintained the high trade surpluses due to the strength of the exporting sector, the importance of oil prices shocks on its domestic economy and in particularly GDP growth and inflation are non-trivial. Perhaps, it poses challenges to the monetary authority and its efforts towards price stability. Particularly, if we consider that time-varying and an increasing appetite for oil and energy in the fast developing Chinese economy, it is clearly evident that the importance of oil prices shocks have been increased. Lastly, we come to "S" of the BRICS and results are as follow:

\section{South Africa}
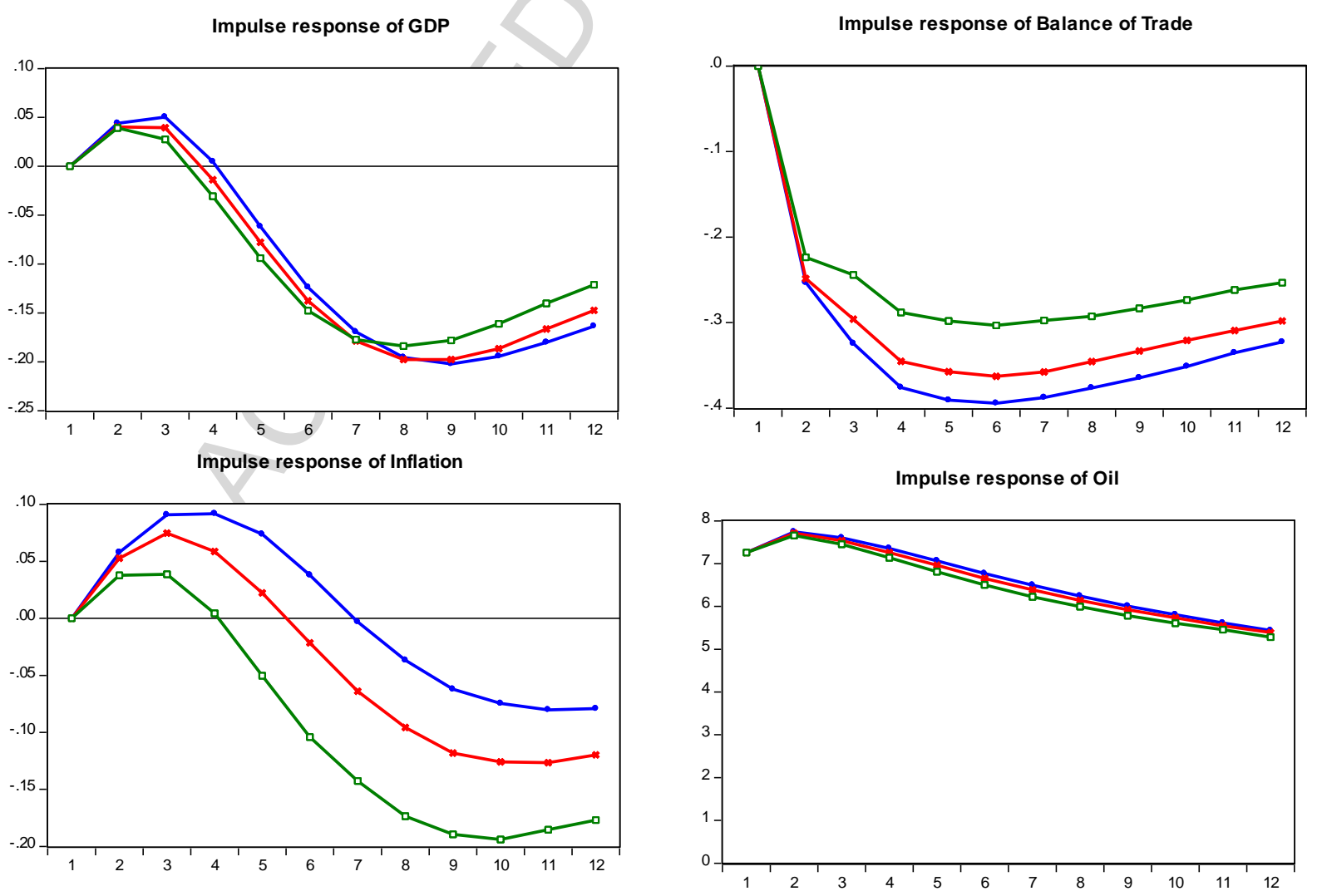

- 2016Q2 $\because 2016 \mathrm{Q} 3 \longrightarrow$ 2016Q4 


\section{Figure-6: Impulse Response of South African GDP, Inflation \& Trade Balance to Oil} Shocks

The impulse response of South Africa's real GDP growth showed an overall negative impact of oil price shocks after an initial minor surge in GDP. The findings add to the study Chisadza et al. (2016) which showed that output is positively affected by oil demand and oilspecific demand shocks, while an oil supply shock has no significant effect ${ }^{24}$. In this regard, our results suggest that despite initial increases, there are long-term negative consequences of oil shocks for GDP. This finding implies that the argument that oil prices increases do not have negative effects on the South African economy needs to be taken with a pinch of salt. Adding further to Chisadza et al. (2016) results, inflation also showed a positive response which faded after a few quarters. The persistence for the few quarters still implies that oil shocks can have implications for price stability, at least in the short to medium term. The impact on trade balance was negative which persisted for several periods (quarters). Without downplaying the importance for the domestic economy, one inference we can draw here is that the external balance of the South African economy is comparatively more vulnerable to oil prices shocks. Interestingly, dissimilar to all the other countries of BRICS the responses in South African inflation showed some dissimilarity in the impact in a different period. It indicated stronger time variation in the response of the South African economy to oil prices shocks. On the external balance, oil prices shocks led to the persistent deterioration of trade balance, which indicates the manifested significance of oil prices shocks for the South African economy's external position.

\section{Conclusion and Policy Implications}

The BRICS have turned out to be a globally significant and influential, economic and political block with its five members constituting almost half of the world's total population (46\% to be precise). Interestingly, along with the socio-cultural, intuitional and political heterogeneities, the BRICS also consists of countries which includes oil importers as well as oil exporters, this heterogeneity is manifested in the varying degree of reliance and dependence on oil and dynamics of its prices. Keeping that in context, in this study we analysed and compared the implications of oil prices shocks for the BRICS economies. For

\footnotetext{
${ }^{24}$ Chisadza et al (2016) used a time invariant SVAR with the sign restriction there are certain limitations of this approach In particular, not allowing for the time variation and imposing sign restrictions limits the view whereas in the subject case we let the data speaks for itself (see Kilian and Lütkepohl, 2017 for detailed insight).
} 
this purpose, a time-varying structural vector autoregressive (TV-SVA) framework was employed in which the sources of time variation were both the coefficients and variancecovariance matrix of the innovations. We contextualise the subject treatise and analysis of association among the variables of interest in the light of net oil trade position of the BRICS members.

The empirical findings lead us to conclude that there are substantial differences and heterogeneities in the responses of the BRICS economies to oil prices shocks in terms of internal and external balances of these economies. In the major oil exporters of the BRICS members i.e. Brazil and Russia, the effects on economic growth were more pronounced in the latter. Similarly, there was asymmetry in the response of inflation and balance of trade, particularly the negative response of Brazilian balance of trade suggests Dutch disease and overall negative impact of oil prices on the balance of trade. It implies the substantial differences in the structure of two economies as well as the greater reliance of the Russian economy on oil than Brazil. In terms of policy setting these findings have profound implications, it is prima facie that the Russian economy reliance on oil is still paramount. The claims of a decrease in such an importance as some studies suggested, do not hold their grounds in the face of empirical evidence. Concomitantly, Russia needs to do more to restructure its economy. In case of major importers i.e. India and China, the results intuitively showed a negative impact on inflation and GDP as well as on the balance of trade, however, there were substantial differences in the intensity of impact and it leads us to conclude that the Indian economy seemed to be rather more vulnerable to oil prices shocks than the Chinese economy. These vulnerabilities were explicitly in the internal and external imbalances of the Indian economy due to oil prices shocks. Nonetheless, compared to the Indian, the Chinese economy and particularly its balance of trade might be able to neutralise the intensity of oil prices shocks due to its strong external position, however, there are still profound implications of oil prices shocks for the domestic Chinese economy in terms of GDP growth and inflation. Nonetheless, the increasing demand and consumption of oil in economies will continue to pose ecological challenges. In terms of monetary policy implication, it also implies that for China and India oil shocks are very important in terms of policy settings. However, given that contrary to China, the monetary authority in India (Reserve Bank of India) has an explicit inflation targeting regime, concomitantly, oil shocks are even more important for its ability to achieve the target. Nonetheless, it also implies that despite the fiscal measures (subsidies and price control) in India to counter oil prices shocks 
on inflation, the results suggest that they are still inflationary. Nonetheless, oil shocks worsened the external position of Indian economy. Hence, India needs to revisit its policy towards the oil market. Besides the absence of inflation targeting regime in China, it does not imply that the importance of oil shocks is negligible, perhaps, instead of inflation, China has an explicit annual output growth rate target which then implies that oil shocks can have profound implications for the policy setting to achieve this target.

The analysis on South Africa also showed negative impacts of oil prices shocks on the economy. The interesting element was stronger time variation in the response of South African economy as compared to the other BRICS countries even in the successive quarters. In terms of policy setting, given that the South African Reserve Bank has adopted the inflation targeting, oil prices shocks and the findings in the subject study have important lessons to draw on. Overall, the BRICS showed asymmetries in the economies in response to oil prices shocks between and within oil exporters and importers, while these asymmetries indicate significant differences in the structure of these economies they also point towards venues of cooperation and stronger trading relationships to overcome the adverse shocks and mutual development. Perhaps, the trading arrangement which can hedge against the adverse shocks to oil importing and oil exporting economies of BRICS is an important oil implication as well a venue for further research in this area.

\section{References}

Amano, R. and Van Norden, S. (1998). Oil prices and the rise and fall of the US real exchange rate. Journal of International Money and Finance, 17, 299-316.

Backus, D. K. and Crucini, M. J. (2000). Oil prices and the terms of trade. Journal of International Economics, 50, 185-213.

Barsky, R. B. and Kilian, L. (2004). Oil and the Macroeconomy since the 1970s. Journal of Economic Perspectives, 18, 115-134.

Benedictow, A., Fjaertoft, D. and Løfsnæs, O. (2013). Oil dependency of the Russian economy: An econometric analysis. Economic Modelling, 32, 400-428.

Bodenstein, M., Erceg, C. J. and Guerrieri, L. (2011). Oil shocks and external adjustment. Journal of International Economics, 83, 168-184.

Boivin, J. (2001). The Feds Conduct of Monetary Policy: Has It Changed and Does It Matter?, Columbia Business School, mimeo.

Bollino, C. A. (2007). Oil prices and the U.S. trade deficit. Journal of Policy Modelling, 29, 729-738. 
Brazilian Ministry of Finance (2014). Economic Data and Trade Statistics, Information on foreign trade, available at [http://brics.itamaraty.gov.br/about-brics/economic-data] accessed on $5^{\text {th }}$ June 2017.

Buetzer, S. and Habib, M. (2012). Global Exchange Rate Configurations: Do Oil Shocks Matter? European Central Bank Working Papers, 1442, 221-232.

Canova, F. (1993). Modelling and Forecasting Exchange Rates with a Bayesian TimeVarying Coefficient Model. Journal of Economic Dynamics and Control, 17, 233-261.

Cashin, P., Mohaddesb, K., Raissic, M. and Raissia, M. (2014). The differential effects of oil demand and supply shocks on the global economy, Energy Economics, 44, 113-134.

Cavalcanti, T. and Jalles, J. T. (2013). Macroeconomic effects of oil price shocks in Brazil and in the United States. Applied Energy, 104, 475-486.

Chib, S., Nardari, F. and Shephard, N. (2002). Analysis of High Dimensional Multivariate Stochastic Volatility Models. Nuffield College, University of Oxford, mimeo.

Chisadza, C., Dlamini, J., Gupta, R. and Modise, M. P. (2016). The impact of oil shocks on the South African economy. Energy Sources, Part B: Economics, Planning, and Policy, 11, 739-745.

Ciccarelli, M. and Rebucci, A. (2003). Measuring Contagion with a Bayesian Time- Varying Coefficient Model, International Monetary Fund, mimeo.

Cogley, T. and Sargent, T.J. (2001). Evolving Post-World War II U.S. Inflation Dynamics. NBER Macroeconomics Annual, 331-373.

Cunado, J., Jo, S. and Gracia, F. P. D. (2015). Macroeconomic impacts of oil price shocks in Asian economies. Energy Policy, 86, 867-879.

Del Negro, M. and Primiceri, G. (2015). Time Varying Structural Vector Autoregressions and Monetary Policy: A Corrigendum. The Review of Economic Studies, 82, 1342-1345.

Dornbusch, R., Fischer, S. and Startz, R. (2001). Macroeconomics, 8th edition, McGraw-Hill. Dreger, C., Kholodilin, K. A., Ulbricht, D. and Fidrmuc, J. (2016). Between the hammer and the anvil: The impact of economic sanctions and oil prices on Russia's ruble, Journal of Comparative Economics, 44, 295-308.

Du, L., He, Y. and Wei, C. (2010). The relationship between oil shocks and china's macroeconomy: an empirical analysis. Energy Policy, 38, 4142-4151.

Dülger, F., Lopcu, K., Burgaç, A. and Balli, E. (2013). Is Russia suffering from Dutch Disease? Cointegration with Structural break. Resources Policy, 38 (4), 605-612. 
Enerdata (2017). Crude oil balance of trade, Global Energy Statistical Yearbook 2016, available at [https://yearbook.enerdata.net/crude-oil-balance-trade.html] accessed on $5^{\text {th }}$ June 2017.

Fanchon, P. and Wendel, J. (1992). Estimating VAR models under non-stationarity and cointegration: alternative approaches for forecasting cattle prices. Applied Economics, 24, 207-217.

Ferderer, J. (1996). Oil price volatility and the Macroeconomy. Journal of Macroeconomics, $18,1-26$.

Fratzscher, M., Schneider, D. and Robays, I.V. (2014). Oil Prices, Exchange Rates and Asset Prices, Working Paper Series NO 1689 / July.

FRED (2017), Crude Oil Prices: Brent - Europe, available at [https://fred.stlouisfed.org/series/DCOILBRENTEU] accessed on $5^{\text {th }}$ June 2017.

Gounder, R. and Bartleet M. (2007). Oil Price Shocks and Economic Growth: Evidence for New Zealand, 1989-2006. Paper Presented at New Zealand Association of Economist Annual Conference, Christchurch, 27th to 29th June.

Halkos, G. E. and Tzeremes, N. G. (2011), Oil consumption and economic efficiency: A comparative analysis of advanced, developing and emerging economies. Ecological Economics, 70, 1354-1362.

Hamilton, J. (1983). Oil and the Macroeconomy since World War II. The Journal of Political Economy, 91, 228-248.

Hamilton, J. (1996). This is what happened to the Oil Price- Macroeconomy Relationship. The Journal of Monetary Economics, 38, 215-220.

Hamilton, J. (2003). What is an Oil Shock? Journal of Econometric, 113, 363-396.

Harvey, A.C. Ruiz, E. and Shephard, N. (1994). Multivariate Stochastic Variance Models. Review of Economic Studies, 61, 247-264.

Hunt, B. L., Laxton, D. and Isard, P. (2001). The Macroeconomic Effects of Higher Oil Prices, Working Paper No 1/14.

Idrisov, G., Kazakova, M. and Polbin, N. (2015). A Theoretical interpretation of the oil prices impact on economic growth in contemporary Russia. Russian Journal of Economic, 1, 257-272.

IMF (2015), World Economic Outlook, available at [http://www.imf.org/external/pubs/ft/weo/2015/02/index.htm] accessed on < 22nd January 2016>. 
Ito, K (2008). Oil prices and Macro-economy in Russia: The co-integrated VAR Model Approach. International Applied Economics and Management letters, 1, 37-40.

Jimenez-Rodriguez, R. and Sanchez, M (2005). Oil shocks and real GDP growth: empirical evidence for some OECD countries. Applied Economics, 37, 201-228.

Kallis, G. and Sager, J. (2017). Oil and the economy: A systematic review of the literature for ecological economists. Ecological Economics, 131, 561-571.

Kilian, L. (2009). Not all oil price shocks are alike: Disentangling demand and supply shocks in the crude oil market. American Economic Review, 99, 1053-1069.

Kilian, L., Rebucci, A. and Spatafora, N. (2009). Oil shocks and external balances, Journal of International Economics, 77, 181-194.

Kilian, L. and Vigfusson, R. J. (2011). Are the responses of the U.S. economy asymmetric in energy price increases and decreases? Quantitative Economics, 2, 419-453.

Kilian, L. and Vigfusson, R. J. (2011b). Nonlinearities in the Oil Price-Output Relationship. Macroeconomic Dynamics, 15, 337-363.

Kilian, L., \& Lütkepohl, H. (2017). Structural Vector Autoregressive Analysis (Themes in Modern Econometrics). Cambridge: Cambridge University Press.

Kim, I-M. and Loungani, P. (1992). The Role of Energy in Real Business Cycle Models. Journal of Monetary Economics, 29, 173-189.

Kim, S., Shephard, N. and Chib, S. (1998). Stochastic Volatility: Likelihood Inference and Comparison with ARCH Models. Review of Economic Studies, 65, 361-393.

Kuboniwa, M. (2014). A comparative analysis of the impact of oil prices on oil-rich emerging economies in the Pacific Rim. Journal of Comparative Economics, 42, 328-339.

Le, T. H. and Chang, Y. (2013). Oil price shocks and trade imbalances. Energy Economics, $36,78-96$.

Lizardo, R. A. and Mollick, A.V. (2010). Oil price fluctuations and US dollar exchange rates. Energy Economics Journal, 32, 399-408.

Mironov, V. V. and Petronevich, A. V. (2015). Discovering the signs of Dutch disease in Russia. Resources Policy, 46, 97-112.

Narayan, P. K. and Sharma, S. S. (2011). New evidence on oil price and firm returns. Journal of Banking and Finance, 35 (12), 3253-3262.

Ou, B., Zhang, X. and Wang, S. (2012). How does China's macro-economy response to the world crude oil price shock: A structural dynamic factor model approach. Computers \& Industrial Engineering, 63, 634-640, 
Ozlale, U. and Pekkurnaz, D. (2010). Oil prices and current account: A structural analysis for the Turkish economy. Energy Policy, 38, 4489-4496

Primiceri, G. E. (2005). Time Varying Structural Vector Auto-regression and Monetary Policy. Review of Economic Studies, 72, Pages 8214 - 852.

Qianqian, Z (2011). The Impact of International Oil price Fluctuation on China's economy. Energy Procedia, 5, 136-1364.

Popova, L., Jabalameli, F. and Rasoulinezhad, E. (2017). Oil Price Shocks and Russia's Economic Growth: The Impacts and Policies for Overcoming Them. World Sociopolitical Studies, 1, 1-31.

Raguindin, C. E. and Reyes, R. G. (2005). The effects of Oil price shocks on the Philippine economy: A VAR Approach. Working paper, University of the Philippines School of Economics, 3, 117-123.

Rautava, J. (2004). The role of oil prices and the real exchange rate in Russia's economy - a cointegration approach. Journal of Comparative Economics, 32, 315-327.

Reynolds, D. B. (2014). World oil production trend: Comparing Hubbert multi-cycle curves. Ecological Economics, 98, 62-71.

Rotemberg, J. J. and Woodford, M. (1996). Imperfect competition and the effects of energy price increases on economic activity. Journal of Money, Credit and Banking, 28, 550-577.

Rafiq, S., Sgro, P. and Apergis, A. (2016). Asymmetric Oil shocks and external balances of major oil exporting and importing countries. Energy Economics, 42-50.

Sakashita, Y. and Yoshizaki, Y. (2016). The Effects of Oil Price Shocks on IIP and CPI in Emerging Countries. Economies, 4, 2-9.

Shephard, N. (1996). Statistical aspects of ARCH and stochastic volatility. Time Series Models in Econometrics, Finance and Other Fields, (edited by D.R. Cox, David V. Hinkley and Ole E. Barndorff-Neilsen), 1-67. London: Chapman \& Hall.

Sims, C. A. (1988). Bayesian skepticism on unit root econometrics. Journal of Economic Dynamics and Control, 12, 463-474.

Sims, C. A. (1993). A 9 Variable Probabilistic Macroeconomic Forecasting Model”, in J. H. Stock and M. W. Watson (Eds.), Business Cycles, Indicators and Forecasting, NBER Studies in business cycles volume 28, 179-214.

Sims, C. A. (1999). Drift and Breaks in Monetary Policy, Princeton University, mimeo.

Sims C. A. ZHA, T. (2006). Were There Regime Switches in US Monetary Policy? American Economic Review, 96, 54-81. 
Smith, M. and Kohn, R. (2002). Parsimonious Covariance Matrix Estimation for Longitudinal Data. Journal of the American Statistical Association, 97, 1141-1153.

Statista (2017), Global oil industry and market, Global Oil Industry and Market - Statistics \& Facts, available at [https://www.statista.com/topics/1783/global-oil-industry-and-market/] accessed on $19^{\text {th }}$ May 2017.

Stock J. H. and Watson, M.W. (1996). Evidence on Structural Instability in Macroeconomic Time Series Relations. Journal of Business and Economic Statistics, 14, 11-30.

Tang, W., Wu, L. and Zhang, Z. (2010). Oil price shocks and their short- and long-term effects on the Chinese economy. Energy Economics, 32, S3-S14.

Tiwari, A. K., Arouri, M. and Teulon, F. (2014). Oil prices and trade balance: a frequency domain analysis for India. Economics Bulletin, 34, 663-680.

Uhlig, H. (1997). Bayesian Vector Auto-regressions with Stochastic Volatility. Econometrica, 65, 59-73.

Verleger, P. K. (1994). Adjusting to Volatile Energy Prices, Peterson Institute.

Varghese, G. (2017). Inflationary effects of oil price shocks in Indian economy. Journal of Public Affairs, 17, 1-9.

Wang, Y., Wu, C. and Yang, L. (2013). Oil price shocks and stock market activities: Evidence from oil-importing and oil-exporting countries. Journal of Comparative Economics, 41, 1220-1239.

Wakeford, J. (2006). The impact of oil price Shocks on the South African Macro economy: History and Prospects, in Accelerated and Shared Growth in South Africa: Determinants, constraints and opportunities. Journal of Economics, 1, 18-20.

Wei, Y. and Guo, X. (2016). An empirical analysis of the relationship between oil prices and the Chinese macro-economy. Energy Economics, 56, 88-100.

World Bank (2016). Russian Economic Report. World Bank in Russia, No 16. 


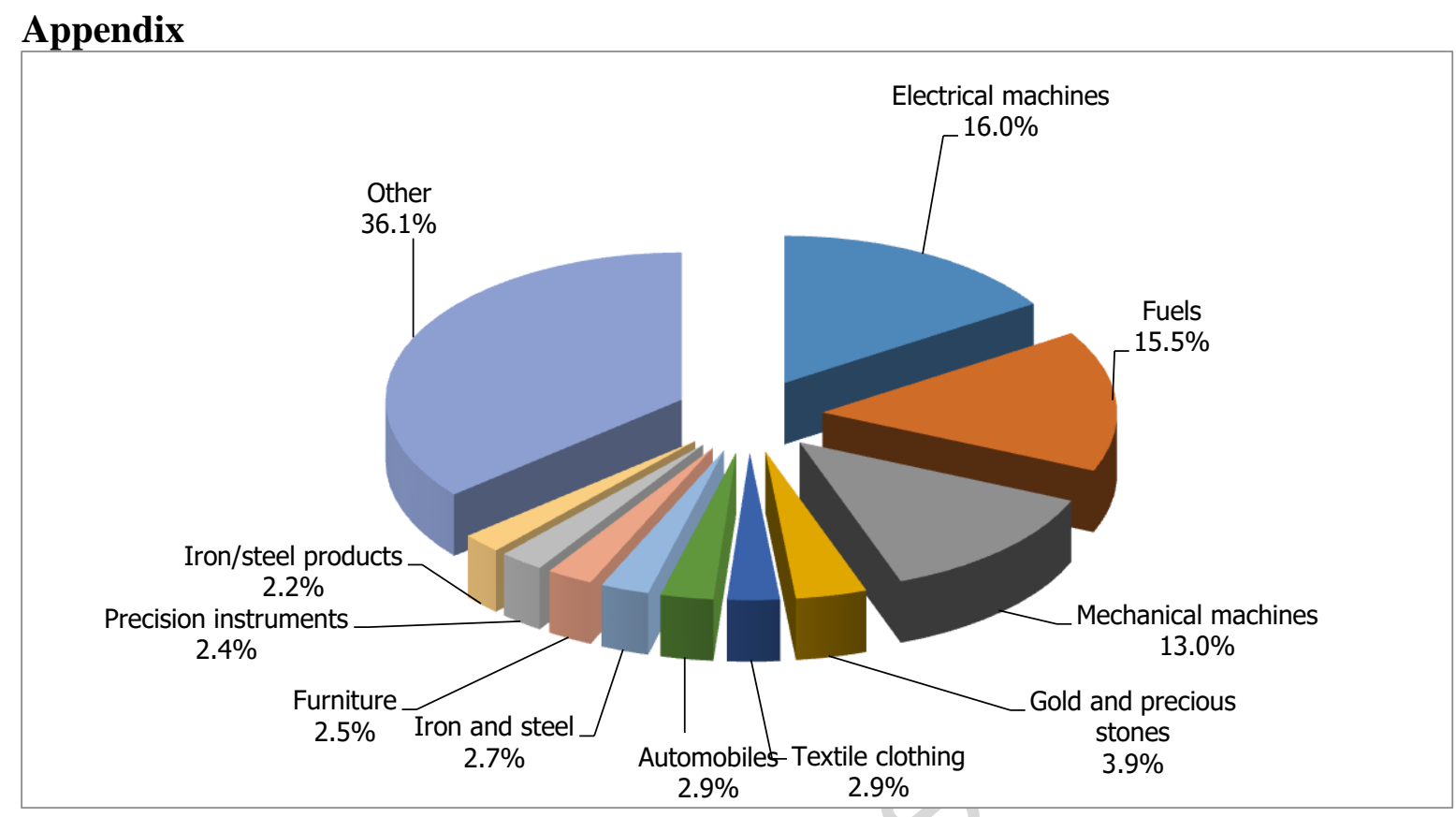

BRICS 10 main product groups exported in 2012, Source; Brazil Ministry of Finance (2014)

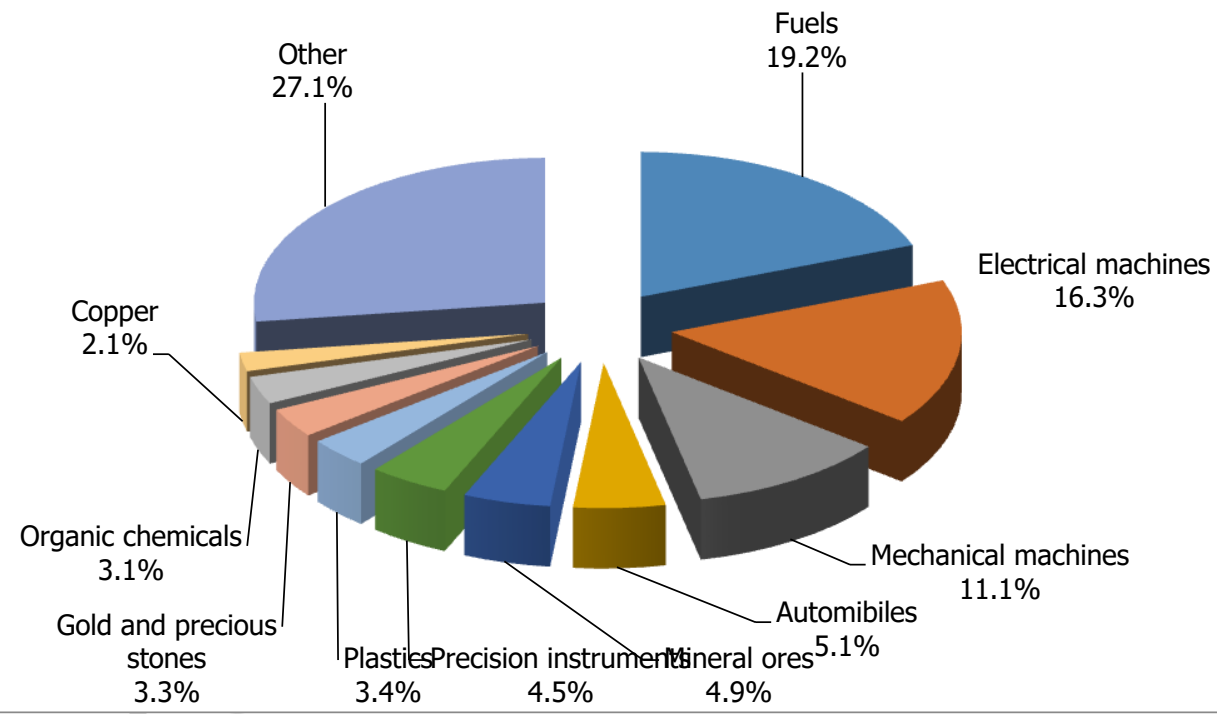

BRICS 10 main product groups Imported in 2012 Source; Brazil Ministry of Finance (2014) 
Oil Shocks \& Implications for the Major Emerging Economies: A Comparative Analysis of BRICS.

A Time Varying Framework to capture the Time Varying dependency of BRICS on Oil and its consumption.

Substantial differences and asymmetries in the response of BRICS economies to the oil shocks.

Profound between and even within the oil exporters and importers.

Russian economy more intensively influenced by the oil shocks than Brazilian.

Indian economy more vulnerable to oil shocks than Chinese.

South African economy showing high Time Variant impact of oil shocks.

Increasing importance and consumption of oil in BRICS continue to pose new set of challenges. 